\title{
A Review on Ergonomic Risk Factors Causing Musculoskeletal Disorders among Construction Workers
}

\author{
Anagha R \\ Dept. Of Civil Engineering \\ TocH Institute of Science and Technology, \\ Arakkunnam, Ernakulam.
}

\author{
Annie Sonia Xavier \\ Dept. Of Civil Engineering \\ TocH Institute of Science and Technology, \\ Arakkunnam, Ernakulam.
}

\begin{abstract}
Most of the injuries, stresses and strains in construction sites, occur due to over-exertion, repetitive work actions and awkward postures of the workers. To reduce the fatigue experienced by the workers and to reduce their unnecessary efforts, ergonomics can prove to be an effective tool. Ergonomics deals with the study of internal and external stresses acting on the human body. Aim of this paper is to review various ergonomic risk factors causing work-related musculoskeletal disorders among construction workers. This paper also reviews different ergonomic risk assessment tools.
\end{abstract}

Keywords-Musculoskeletal disorders,risk factor, ergonomics, construction worker,awkward posture.

\section{INTRODUCTION}

According to Wang et al. (2015), it has been evidenced by a number of studies that construction industry is one of the most hazardous work place industries with high rates of fatalities, injuries and health problems. In the construction industry, highly physically demanding tasks expose construction workers to a number of well-recognized work related musculoskeletal disorder (WMSD) risk factors such as repetitive motion, high force exertion, awkward body posture, vibration, and contact force. They are also known as cumulative trauma disorders, repetitive strain injuries, repetitive motion disorders, and overuse syndrome. This paper aims to review various ergonomic risk factors causing MSDs among construction workers.

\section{MUSCULOSKELETAL DISORDERS}

As per Canadian Centre for Occupational Health, and Safety (CCOHS) 2013, musculoskeletal disorders (MSDs) are a group of painful disorders of soft tissues (i.e., muscles, tendons, nerves, joints, cartilage, and ligaments) They are also known as cumulative trauma disorders, repetitive strain injuries, repetitive motion disorders, and overuse syndrome. Most WMSDs develop over time and are caused either by the work itself or by the employees' working environment. Inyang et al.(2012) suggested that based on the cause of injury, WMSDs can be categorized into sprains, strains, and cumulative trauma disorders. As suggested by Wang et al.(2015), sprains and strains are injuries in the joints or muscular tears caused by high levels of force that take place during a single event of lifting, lowering, pushing, pulling, or carrying. In such an event, the physical forces exerted are beyond one's physiological capability. The other type of WMSDs is cumulative trauma disorders that result from performing a task repetitively, even if the load is relatively small (i.e., repetitive motions such as bricklaying), or from a worker's body being in an uncomfortable position (i.e., awkward body postures such as tying rebar) .It was observed that The most common WMSDs among construction workers are carpal tunnel syndrome, tendonitis, tennis elbow, trigger finger, sciatica, herniated discs, and low back pains Symptoms of these disorders include pain, aching, discomfort, numbness, tingling, and swelling that normally occur in the back, shoulders, neck, legs, wrists, fingers, elbows, and arms. At a construction site, the typical tasks associated with WMSDs include, but are not limited to, lifting and carrying heavy objects, laying blocks, handling pipe work, paving slabs and curbs, installing plasterboards, installing mechanical and electrical (M\&E) equipment, and working at height.

\section{ERGONOMIC RISK FACTORS IN CONSTRUCTION INDUSTRY}

Physical exposures, also referred to as physical risk factors, are the hazardous operations or conditions that expose workers to WMSD risks. They involve repetitive motions, high force exertions, awkward postures, and poor working conditions such as extreme temperature and high vibration. Jaffar et al. (2011) studied the ergonomics risk factors in construction industry. The most significant ergonomics risk factors identified were awkward posture in handling job task, force and repetition of specific movement including vibration. Other ergonomics risk factor included uncomfortable static position, contact stress of muscles and tendon and also extreme temperature condition. They explained risk factor exposure as an early warning of progressively more serious problems i.e. physical signs and symptoms that can lead to serious injury. Long-term exposure to risk factors will reduce the quality of life. Injury risks increase whenever work requires a person to perform tasks with body segments outside their neutral range in a deviated posture. Inayang et al. (2012) studied the exposure of workers to one or multiple ergonomic risk factors (awkward postures, static force, vibration, repetition, environmental risk, contact stress) and thus varying risks of developing musculoskeletal disorders. Their study presented resultant economic losses and adverse social and health impact of work related musculoskeletal disorders resulting from current construction practices. Shoubi et al. (2013) investigated all significant 
factors which should be taken into account in an ergonomic program to develop the best remedial method against the costly, harmful and irreversible work related injuries. Some probable and common tasks and their related ergonomic risk factors and some remedies for them were investigated. It was suggested that conducting an appropriate ergonomic program can be so effective in mitigating or even preventing the work related MSDs in various industries specifically construction industry.

\section{A. Quantitative and qualitative assessment of risk factors}

Ijaz et al. (2020) conducted quantitative and qualitative assessment of musculoskeletal disorders and socioeconomic issues of workers of brick industry in Pakistan. They identified relation between 5 work stages and MSDs in 9 body parts and also found socioeconomic sufferings inflicted by the industry .their study revealed that about $96 \%$ workers involved in mixing and moulding complained tiredness at end of day. Similarly, $90 \%$ male and $83 \%$ female staff performing spreading task suffered tiredness after their duty hours. Workers engaged in different tasks reported varying levels of pain in observed body parts. Digging and carrying jobs caused significant pain in body parts including neck, upper back, shoulders, lower back and hips. Mixing and moulding emerged most dangerous activities for most of the body parts It was identified that all observed work tasks during manufacturing and transportation of bricks are equally dangerous for pain generation in lower back. Many socioeconomic issues like residency of workers in muddy house $(83 \%)$ low monthly income (<90.3\$) of $83 \%$ workers, higher tendency of alcoholism and smoking in men, lack of health facilities and higher illiteracy rate were also identified. The enhanced musculoskeletal disorders during brick making process render the brick industry unhealthy for work. This dismal picture requires an improvement in quality of life and occupational environment of workers of the industry. They suggested that well organized duty timings, modified working posture, job rotation and preliminary training might manage these miseries and the output of the brick industry may increase many fold.

\section{B. Awkward posture - A major risk factor}

From previous studies, it was observed that awkward and incorrect posture is one of the major ergonomic risk factors causing work related musculoskeletal disorders among workers..It induces strain in joints and limbs of the workers. The awkward working postures can be observed and analyzed using various ergonomic tools. Previous studies on various ergonomic risk assessment tools and their reliability is described in the following section.

\section{STUDIES ON ERGONOMIC RISK ASSESSMENT TOOLS}

Chiasson et al. (2012) presented a comparison between eight different methods for determining risk factors for work related musculoskeletal disorders. The Quick Exposure Check (QEC), the Ergonomic Workplace Analysis developed by the Finnish Institute of Occupational Health (FIOH), ACGIH's Hand Activity Level threshold limit values method (HAL), the Job Strain Index (JSI), the OCRA index, the EN 1005-3 standard, the Rapid Upper Limb Assessment (RULA) and the Rapid Entire Body Assessment (REBA) methods were all used to assess 224 workstations involving 567 tasks in various industrial sectors. The results are compared using three risk categories (low, moderate, high). Data were gathered using video and measurements taken at the workstations. A questionnaire was also administered to employees participating in the study. The findings reveal that the various methods differ in their analyses of the same workstation. Correlation was highest between RULA and REBA. The QEC Hand/wrist and OCRA Hand/wrist/elbow indices showed similar results for the number of workstations classified as high risk, but did not classify the same workstations in this category. These results provide a better understanding of the differences between various risk assessment methods. Bhandare et al. (2013) described that REBA and RULA are techniques to quantize the fatigue experienced by the worker while manually lifting loads. These assessments were carried out by a procedural analysis of body postures involved. The fatigue involved in a particular operation was quantified and accordingly changes in the work method for system improvement were suggested. These techniques helped in process refinement by identifying actions causing high fatigue. The work was carried out on spiral press machine which is used for capacitor flattening. The methods REBA \& RULA help as a tool to asses and quantify the fatigue involved in existing work methods which otherwise (fatigue) is a subjective variable. Ahankoob et al. (2013) suggested that applying the EERFM ( Effective Ergonomic Risk Factors) strategy with appropriate control measures concurrently in a regular basis remove the barrier to quality, productivity and human performance Monitoring (EERFM).

Lee et al. (2013) used Ovako Work Posture Analyzing System (OWAS) to analyze the working postures of construction workers in building the foundations of a $\log$ cabin. There were three objectives for this study: first, to provide an overview of postural distribution of construction workers in building the foundations of a log cabin; second, to identify the most problematic working postures and jobs of construction workers in building the foundations of a $\log$ cabin; third, to propose recommendations for work improvements for construction workers in building the foundations of a log cabin. Three construction workers, with an average work experience of 40 years, participated in this study. Eight elementary jobs of building the foundations of a log cabin were videotaped at a construction site and analyzed later in the laboratory. For an overall distribution of trunk postures, OWAS identified that a bent and twisted trunk posture (34\%), which fell into action category 3, was the major poor posture for construction workers. This study also identified that tying beams with steel bars, assembling column templates, and cement grouting of the ground were the 3 principal jobs in which workers building the foundations exhibited poor working posture.

Purnomo et al. (2016) adopted REBA (Rapid Entire Body Assessment) analysis to analyze construction workers' posture. From the study sample, $80 \%$ of construction workers had poor posture and had a high risk for developing musculoskeletal conditions due to their traditional construction methods and the limited tools they used. All three workers were at a high risk for a musculoskeletal disorder and needed to improve their postures immediately. All three postures were improved by adding simple tools such 
as a desk or a small seat. After applying these tools and improvements, all of the workers lowered their REBA scores. The first worker's REBA score decreased 4 points, falling from 8 to 4 . The second worker's REBA score decreased 5 points, falling from 11 to 6 . And the third worker's REBA score also decreased 5 points, falling from 10 to 5 .

Vachhani et al. (2016) applied ergonomics assessment tools REBA (rapid entire body assessment) and QEC (quick exposure check) on workers to assess the risk levels. Comparison of QEC and REBA score was done with Wilcoxon signed rank test in SPSS. The result shows that most workers are at higher and medium risk on residential construction site. From results it was suggested that the tasks need to be redesigned. They also suggested some measures to reduce the risk of MSD. Kulkarni et al. (2017) conducted a study by using RII \& PATH method to assess the posture of the workers in various construction tasks. The PATH and RII both identified that the shoulders, knees, legs and back were at a high risk for developing CTD's due to the abducted lower body postures, the repeated actions, and the flexion and extension of the wrists involved when the workers perform task. The outcomes of both the PATH and RII assessments indicate that there was a high risk of developing Cumulative Trauma Disorders (CTD's) and musculoskeletal disorders (MSD's). PATH assessments show that each method identified awkward postures and high repetitions in the arm, wrist, and elbow locations which contributed to the reported injuries.

Kulkarni et al. (2018) conducted study to assess and understand the level of ergonomics in various tasks in the construction industry. Another aim of the study was to find the level of musculoskeletal disorders and suggest corrective measures for every task having high risk factor. The study was conducted by using the Rapid Upper Limb Assessment and Rapid Entire Body Assessment techniques to assess the posture of the workers in various construction tasks. Limited set of construction activities like granite cutting, brickwork and plastering were analyzed.

\section{V.CONCLUSIONS}

In construction sites, most of the injuries, stresses and strains occur due to over-exertion and repetitive work actions of the workers. To reduce the fatigue experienced by the workers and to reduce their unnecessary efforts, ergonomics can prove to be an effective tool. Postural analysis can be a powerful technique for assessing work activities. This paper reviewed various ergonomic risk factors that can be a cause for work related MSDs among construction workers. Different ergonomic tools to assess these risk factors were also reviewed in this study.

\section{REFERENCES}

[1] A Ahankoob and A Charehzehi, "Mitigating Ergonomic Injuries In Construction Industry", IOSR Journal of Mechanical and Civil Engineering , 6(2),36-42,2013.

[2] A Bhandare ,P Bahirat ,V Nagarkar and A Bewoor A,'Postural Analysis And Quantification Of Fatigue By Using RULA And REBA Techniques", International Journal of Mechanical and Production Engineering, 1(3), ISSN: 2320-2092,2013.

[3] D Wang, F Dai and X Ning," Risk Assessment of Work-Related Musculoskeletal Disorders in Construction: State-of-the-Art Review", Journal of Construction Engineering and Management, 1-15,2015.

[4] H Purnomo and A E Apsari , "REBA Analysis For Construction Workers In Indonesia", Journal of Built Environment, Technology and Engineering, 1,1-7,2016.

[5] M Chiasson , D Imbeau , K Aubry and A Delisle ,"Comparing The Results Of Eight Methods Used To Evaluate Risk Factors Associated With Musculoskeletal Disorders", International Journal of Industrial Ergonomics $42,478-488,2012$.

[6] M Ijaz ,S Rashid Ahmad ,M Akram,W Ullah Khan ,N A Yasin and F Ali Nadeem, "Quantitative and qualitative assessment of musculoskeletal disorders and socioeconomic issues of workers of brick industry in Pakistan", International Journal of Industrial Ergonomics ,76,1-9,2020.

[7] M V Shoubi, A S Barough and A Rasoulijavaheri,"Ergonomics Principles And Utilizing It As A Remedy For Probable Work Related Injuries In Construction Projects" , International Journal of Advances in Engineering \& Technology, 6(1), 232-245,2013.

[8] N Inyang , M Al-Hussein ,M El-Rich and S Al-Jibouri," Ergonomic Analysis and the Need for Its Integration for planning and assessing construction tasks", Journal Of Construction Engineering And Management, 138,1370-1376,2012.

[9] N Jaffar ,A H Abdul-Tharim ,I F Mohd-Kamar and N S Lop ,"A Literature Review of Ergonomics Risk Factors in Construction Industry", Procedia Engineering, 20,89-97,2011.

[10] T Lee and C Hana, "Analysis of Working Postures at a Construction Site Using the OWAS Method", International Journal of Occupational Safety and Ergonomics (JOSE), 19(2), 245-250,2013.

[11] T R Vachhani,S Pataskar and S Sawant ,'Ergonomics Risk Assessment By REBA And QEC On Residential Construction Site", International Journal Of Advance Research In Science And Engineering,5(7),200207,2016 .

[12] V S Kulkarni and R V Devalkar, "Ergonomic Analysis of Postures of Building Construction Workers Using RII \& PATH Method," International Journal of Innovative Research in Science, Engineering and Technology, 6(1), 2347-6710,2017.

[13] V S Kulkarni and R V Devalkar,"Postural Analysis Of Building Construction Workers Using Ergonomics", International Journal of Construction Management, 1562-3599,2018. 